\title{
Racial differences in blood pressure: genetic and environmental factors
}

\author{
P. S. SeVER \\ M.A., M.B., B.Chir., Ph.D., F.R.C.P. \\ Department of Clinical Pharmacology and Therapeutics, St Mary's Hospital Medical School, London W2 1PG
}

\section{Summary}

The present study shows that different racial groups (black and white) living in a similar environment have different levels of blood pressure. Furthermore the same ethnic group living in a dissimilar environment also has different blood pressure distributions: thus it seems that both genetic (racial) and environmental factors influence the levels of arterial pressure.

The data presented also reveal that there are racial differences in certain biochemical correlates of blood pressure, namely plasma renin activity and plasma noradrenaline concentration, and it is suggested that these observations may underline differing pathogenetic mechanisms for blood pressure elevation in blacks and whites.

\section{Introduction}

There is now a considerable weight of evidence to support the view that both genetic and environmental factors ultimately determine levels of arterial pressure. High blood pressure tends to run in families and in population studies the familial factor is evident throughout the whole of the blood pressure range. Miall and Chinn (1974) demonstrated a strong correlation between the diastolic pressure of first degree relatives. Although both genetic and environmental influences could contribute to the familial resemblance in blood pressure, the twin studies of Feinleib et al. (1975) provided more supportive evidence for the importance of the genetic factor.

From experimental animal models of hypertension it has been possible, at least in part, to unravel some of the complexities of the geneticenvironmental interaction. Dahl's salt-sensitive strain of rats become hypertensive when salt solutions replace water in the diet (Dahl, Heine and Tassinari, 1962). Moreover, the haemodynamic response to sodium in this strain differs markedly from that observed in the Dahl resistant (control) strain (Tobian, 1977). Evidence for a genetic factor in this model has been provided by Bianchi who showed that salt sensitivity could be conferred on the resistant strain by transplanting a kidney from sensitive to resistant animals (Bianchi et al., 1974).
In another animal model (the spontaneously hypertensive rat), environmental stimuli can be shown to produce abnormal blood pressure elevation (Hallbäck, 1975). It has been proposed that such stimuli interact with a genetically determined hyper-reactivity of the defence mechanism to induce a neurogenically mediated rise in pressure.

In each of these models, both genetic and environmental factors play a role in raising arterial pressure

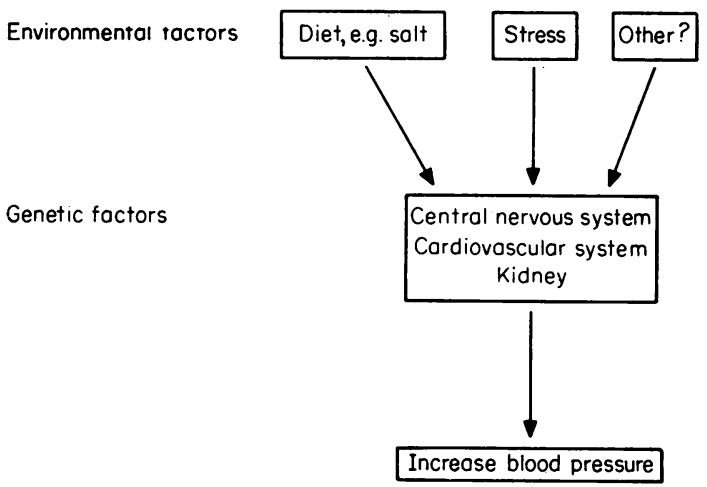

FIG. 1. Possible interrelations of environmental and genetic factors in blood pressure elevation.

(Fig. 1). Although it is difficult to extrapolate information derived from such animal models to man, it is likely that a similar interplay between genetic and environmental factors is responsible for blood pressure elevation in man.

\section{Racial differences in blood pressure}

Simple comparison of blood pressure distribution curves reveals marked differences between various racial groups. However, because it is impossible from such data to discriminate between genetic and environmental influences, an attempt has been made to resolve some of these problems firstly by comparing 2 different ethnic groups in a similar environment, and secondly by comparing the same ethnic group in 2 dissimilar environments. 


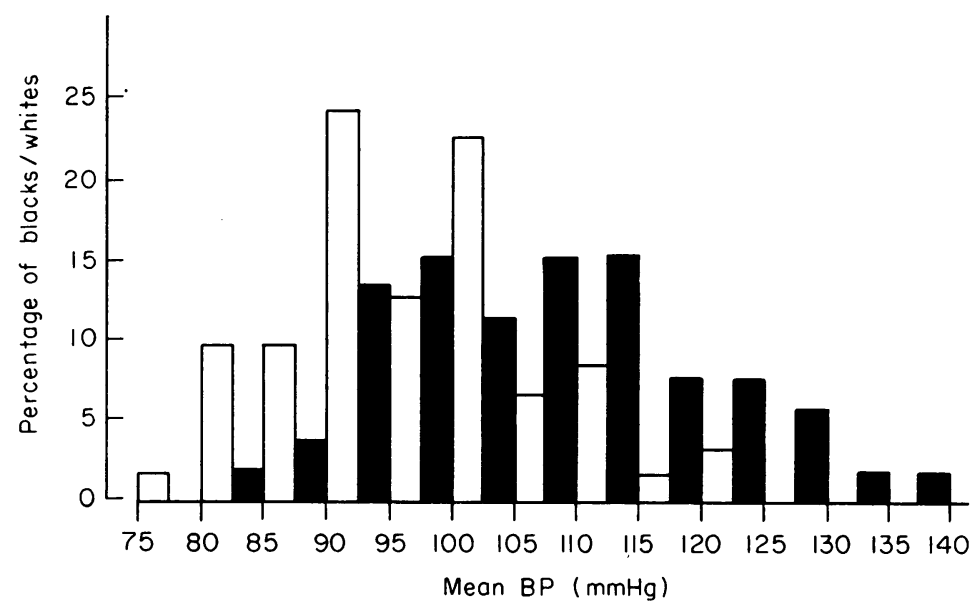

Fig. 2. Frequency distribution of mean blood pressure in white (unfilled bars) and black (filled bars) subjects in a factory popula $-\rightarrow$ tion.

In these studies, in addition to measurements of blood pressure, the author has examined possible correlates of blood pressure, namely plasma noradrenaline (an estimate of the activity of the sympathetic nervous system), plasma renin activity and urinary electrolyte excretion.

In the first study (Sever et al., 1979b), 115 factory workers were investigated. All workers had similar jobs and lived in the same district. Black (West Indian) subjects were age- and sex-matched with whites. Blood pressures (Fig. 2) were higher in $\stackrel{\circ}{?}$ blacks than whites and rose with age in both groups. $\overrightarrow{0}$ Of the blacks, $28 \%$ had a blood pressure $>140 / 90^{\circ}$ $\mathrm{mmHg}$ and $8 \%>160 / 95 \mathrm{mmHg}$, the comparable ${ }^{\Phi}$ figures for whites being $8 \%$ and $3 \%$ Plas noradrenaline concentrations rose with age $\dot{\text { gn }}$ ? blacks and whites and were similar in both ethi⿳⺈ $\overrightarrow{0}$ groups (black $418 \pm 171$ s.d. pg/ml; white $407 \pm 109$. $\mathrm{pg} / \mathrm{ml}$ ). Plasma renin activity (Fig. 3) was $55 \%$ lower in blacks and this difference could not bes

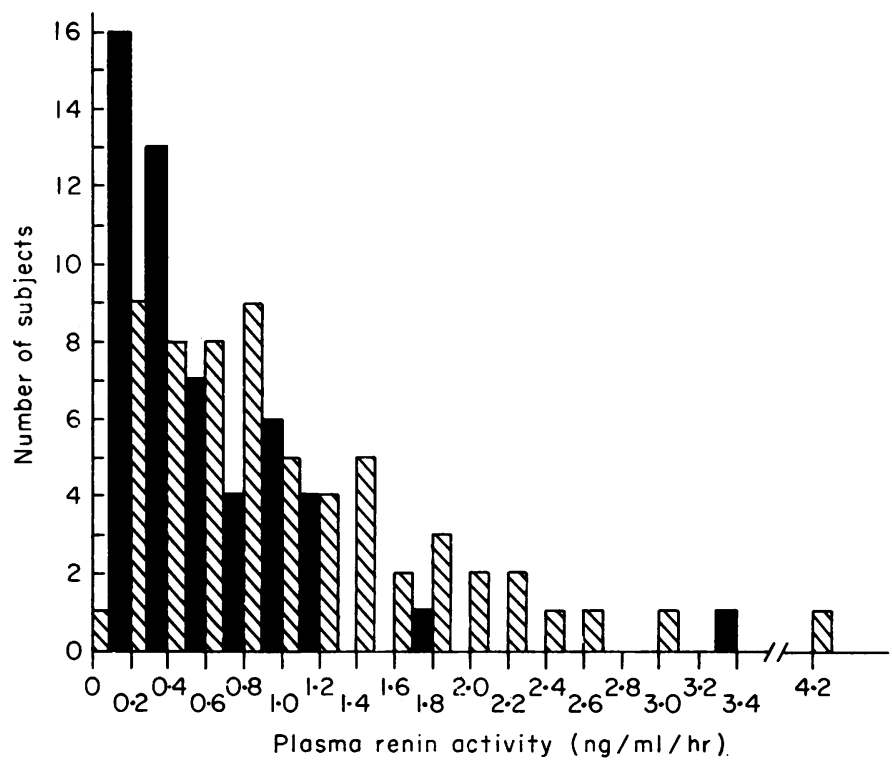

FIG. 3. Frequency distribution of plasma renin activity in white and black subjects in a factory population. mean white (⿻ $1 \cdot 114 \pm 0.789$; mean black $(\square) 0.500 \pm 0.537 . P<0.001$ (reproduced by kind permission of the Editor of Clinical and Experimental Hypertension). 
explained by differences in the renal excretion of sodium (or potassium) as estimated by the urine electrolyte/creatinine ratio, which was the same in both races.

In a study of 100 untreated hypertensive blacks and whites referred to a hospital clinic (Sever et al., 1979a), the observations were broadly similar. Plasma renin activity was again $50 \%$ lower in hypertensive blacks than hypertensive whites despite similar urinary sodium excretion. In white hypertensives, amongst the younger subjects $(<45$ years), approximately $30 \%$ had raised plasma noradrenaline concentrations, in contrast with black hypertensives in whom no such abnormality was found. This observation of higher concentrations of noradrenaline in younger white hypertensives accounts for the failure to demonstrate the normal rise of plasma noradrenaline with age in this group (Fig. 4).

From these studies, it was evident that certain biochemical correlates of blood pressure differed in the 2 racial groups and might indicate differences in the pathogenesis of high blood pressure in the 2 races. Other investigators have reported racial differences in the urinary kallikrein response to salt depletion (reduced in blacks) (Levy et al., 1977); an increased blood pressure response to sodium loading in blacks (Luft et al., 1979) and lower levels of plasma dopamine- $\beta$-hydroxylase in blacks (Voors et al., 1979). These observations add further support to the contention that factors maintaining blood pressure differ significantly in blacks and whites.
In a second series of investigations, the author compared blood pressure and associated factors in tribal and urban Xhosa people of southern Africa, in an attempt to minimize ethnic differences and to identify environmental factors that might be associated with the rise in blood pressure that is consequent upon urbanization (Sever et al., 1980).

In this study of 141 urban and 133 tribal blacks, ages were well matched and blood pressure distribution curves showed marked differences between groups (Fig. 5). Blood pressure rose little with age in the tribal group (Fig. 6) which contrasted with the steep rise with age in the urban population.

Weight, ponderal index and other correlates of obesity were significantly greater in the urban population and were strongly correlated with blood pressure. Urine sodium concentration and urine sodium/creatinine ratio were significantly lower in the tribal group (Table 1), but did not correlate with arterial pressure. It must be emphasized, however, that urinary sodium excretion determined from spot samples of urine are crude measures of overall sodium status. Determinations of plasma noradrenaline and plasma renin activity revealed no differences between tribal and urban subjects.

The rise in arterial pressure associated with urbanization amongst this black population was associated with increased body weight and the development of obesity. The role of increasing dietary salt in the blood pressure elevations was more uncertain. However, if ultimately high blood pressures only develop in those subjects with a genetic predisposition to the effects of salt loading,

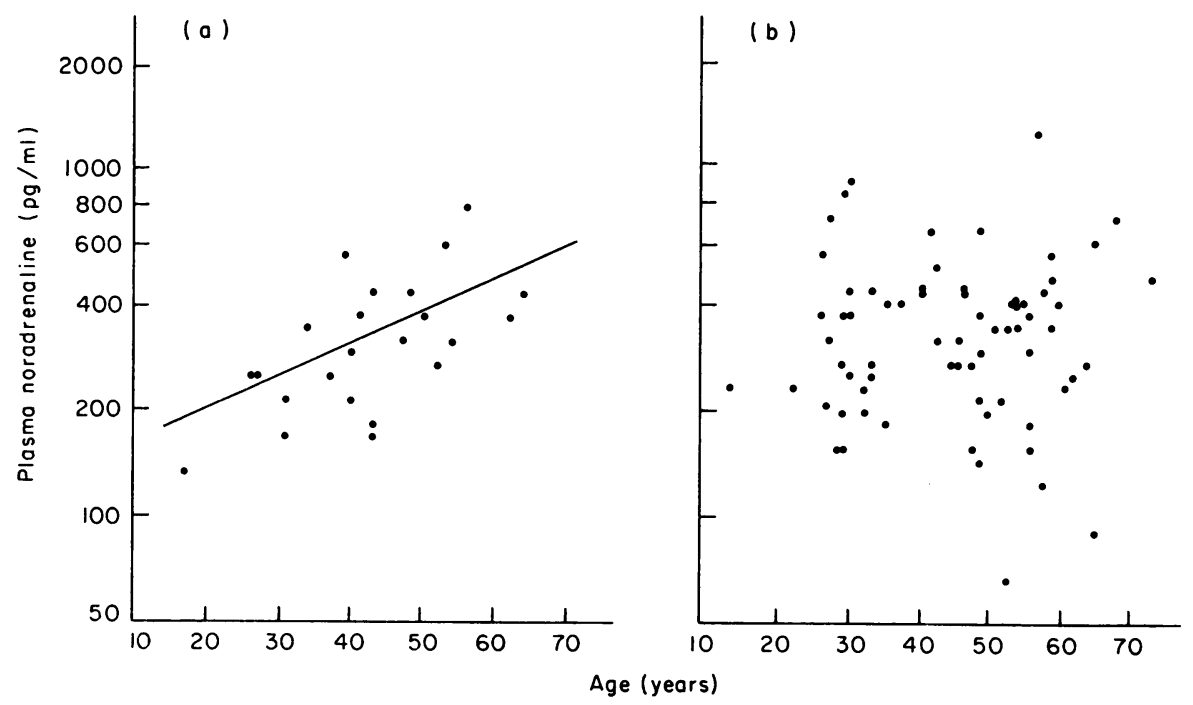

Fig. 4. Relationship between plasma noradrenaline concentration and age in hypertensive (a) black and (b) white subjects. 


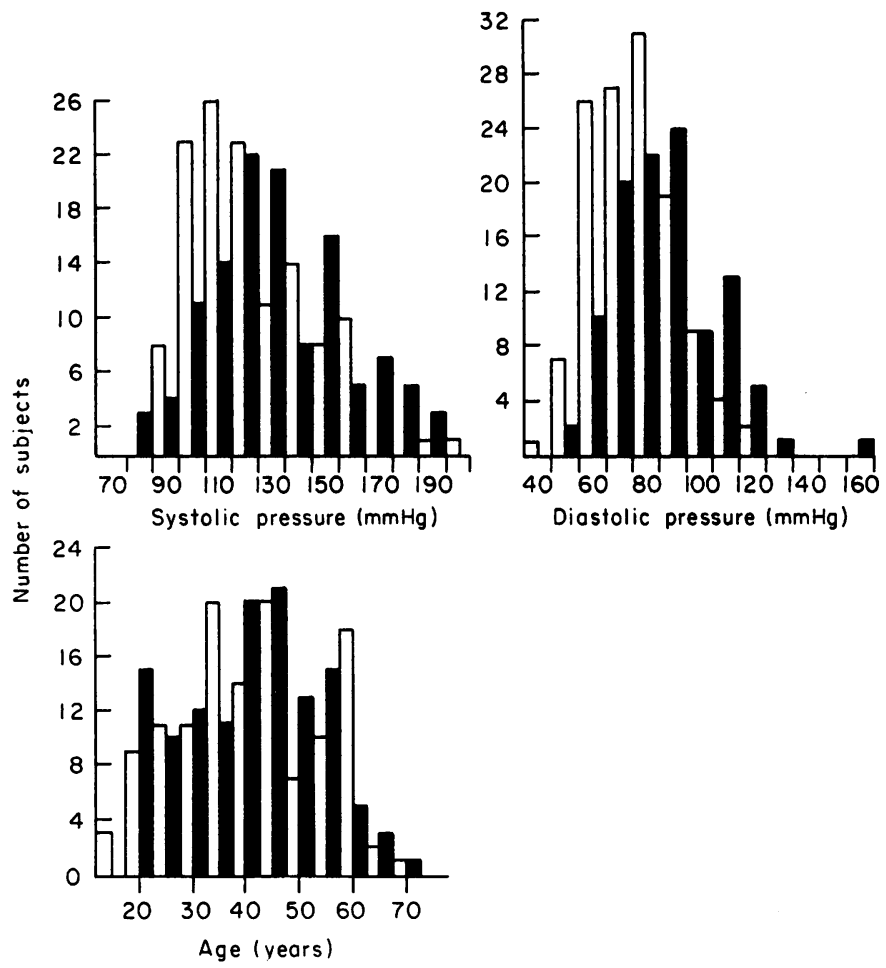

Fig. 5. Frequency distribution of systolic and diastolic blood pressures and age in rural (unfilled bars) and urban (filled ba Xhosa (reproduced by kind permission of the Editor of The Lancet).

TABLE 1. Data for 2 populations-mean (s.d.)

\begin{tabular}{|c|c|c|c|c|c|c|}
\hline & \multicolumn{3}{|c|}{ Tribal } & \multicolumn{3}{|c|}{ Urban } \\
\hline & $\begin{array}{r}\text { All } \\
(n=126) \\
\end{array}$ & $\begin{array}{r}\text { Men } \\
(n=35)\end{array}$ & $\begin{array}{l}\text { Women } \\
(n=91)\end{array}$ & $\begin{array}{r}\text { All } \\
(n=125) \\
\end{array}$ & $\begin{array}{r}\text { Men } \\
(n=64)\end{array}$ & $\begin{array}{l}\text { Womes } \\
(n=61)\end{array}$ \\
\hline Age (years) & $42 \cdot 7(13 \cdot 3)$ & $43 \cdot 7(9 \cdot 6)$ & $42 \cdot 3(14 \cdot 6)$ & $42 \cdot 3(12 \cdot 7)$ & $46 \cdot 1(13 \cdot 9)$ & $38 \cdot 2(9 \cdot 7)$ \\
\hline Height (cm) & $161 \cdot 0(8 \cdot 4)$ & $167 \cdot 9(5 \cdot 5)$ & $158 \cdot 0(7 \cdot 7)$ & $160 \cdot 4(9 \cdot 1)$ & $166 \cdot 8(6 \cdot 4)$ & $153.6(6 \cdot 2)$ 㺃 \\
\hline Weight (kg) & $66 \cdot 9(15 \cdot 1)$ & $63 \cdot 5(10 \cdot 9)$ & $68 \cdot 3(16 \cdot 3)$ & $76 \cdot 8(15 \cdot 8)^{*}$ & $73.5(12.5)^{*}$ & 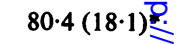 \\
\hline $\begin{array}{l}\text { Skin fold thickness (mm) } \\
\text { (subscapular) }\end{array}$ & $18 \cdot 5(10 \cdot 6)$ & $12 \cdot 0(6 \cdot 9)$ & $21 \cdot 1(10 \cdot 7)$ & $21.9(11.4)^{*}$ & $16 \cdot 0(7 \cdot 5)^{*}$ & $28 \cdot 6(11 \cdot 4)$ 弯 \\
\hline Ponderal index $\left(\mathrm{g} / \mathrm{cm}^{2}\right)$ & $2.59(0 \cdot 58)$ & $2 \cdot 26(0 \cdot 34)$ & $2 \cdot 73(0 \cdot 60)$ & $3.01(0.69)^{*}$ & $2.63(0.40)^{*}$ & $3.40(0.72) \frac{5}{7}$ \\
\hline $\begin{array}{l}\text { Systolic pressure } \\
\text { (supine, mmHg) }\end{array}$ & $121 \cdot 9(21 \cdot 7)$ & $129 \cdot 0(18 \cdot 7)$ & $119 \cdot 2(22 \cdot 2)$ & $134 \cdot 2(29 \cdot 8)^{*}$ & $140 \cdot 0(28 \cdot 8)^{*}$ & $128 \cdot 2(29 \cdot 9)$ \\
\hline $\begin{array}{l}\text { Diastolic pressure } \\
\text { (supine, } \mathrm{mmHg} \text { ) }\end{array}$ & $76 \cdot 4(16 \cdot 4)$ & $78 \cdot 1(15 \cdot 0)$ & $75 \cdot 8(17 \cdot 0)$ & $86 \cdot 4(19 \cdot 5)^{*}$ & $88 \cdot 2(19 \cdot 4)^{*}$ & $84.4(19 \cdot 5)$ \\
\hline $\begin{array}{l}\text { Mean pressure } \\
\text { (supine, } \mathrm{mmHg} \text { ) }\end{array}$ & $91 \cdot 6(16 \cdot 8)$ & $95 \cdot 1(14 \cdot 9)$ & $90 \cdot 3(17 \cdot 4)$ & $102 \cdot 3(21 \cdot 6)^{*}$ & $105 \cdot 5(20 \cdot 8)^{*}$ & $99 \cdot 0(22 \cdot 1)$ \\
\hline Supine pulse (beats/min) & $73 \cdot 6(11 \cdot 7)$ & $70 \cdot 2(13 \cdot 5)$ & $74.9(10 \cdot 8)$ & $72 \cdot 0(11 \cdot 3)$ & $70 \cdot 1(11 \cdot 5)$ & 73.9 (10.9墨. \\
\hline $\begin{array}{l}\text { Plasma renin activity } \\
(\mathrm{pg} / \mathrm{ml} / \mathrm{hr})\end{array}$ & $589(744)$ & 700 (1447) & $546(750)$ & $661(1721)$ & $582(1447)$ & 745 (1980) \\
\hline $\begin{array}{l}\text { Plasma noradrenaline } \\
(\mathrm{pg} / \mathrm{ml})\end{array}$ & $291(297)$ & $394(310)$ & $252(284)$ & $242(295)$ & $243(338)^{*}$ & $241(246$ \\
\hline Urine sodium (mmol/l) & $81(56)$ & $88(62)$ & $78(54)$ & $109(57)^{*}$ & $108(56)$ & 109 (59) \\
\hline Urine potassium (mmol/l) & $30(25)$ & $46(34)$ & 24 (19) & $29(20)$ & $31(22)^{*}$ & $30(19)$ \\
\hline Urine creatinine (mmol/l) & $7 \cdot 3(5 \cdot 2)$ & $10 \cdot 1(5 \cdot 3)$ & $6 \cdot 3(4 \cdot 8)$ & $6 \cdot 8(4 \cdot 6)$ & $7 \cdot 7(5 \cdot 2)$ & $5.9(3.6$ \\
\hline Urine sodium/creatinine & $13 \cdot 7(8 \cdot 4)$ & $11 \cdot 3(8 \cdot 8)$ & $14 \cdot 5(8 \cdot 2)$ & $19 \cdot 4(9 \cdot 3)^{*}$ & $17 \cdot 5(9 \cdot 5)^{*}$ & 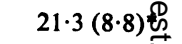 \\
\hline Urine potassium/creatinine & $4 \cdot 2(2 \cdot 3)$ & $4 \cdot 9(3 \cdot 2)$ & $4 \cdot 0(1 \cdot 9)$ & $4 \cdot 6(2 \cdot 2)$ & $4 \cdot 3(2 \cdot 3)$ & $5 \cdot 0(2 \cdot 1)^{*}$ \\
\hline
\end{tabular}




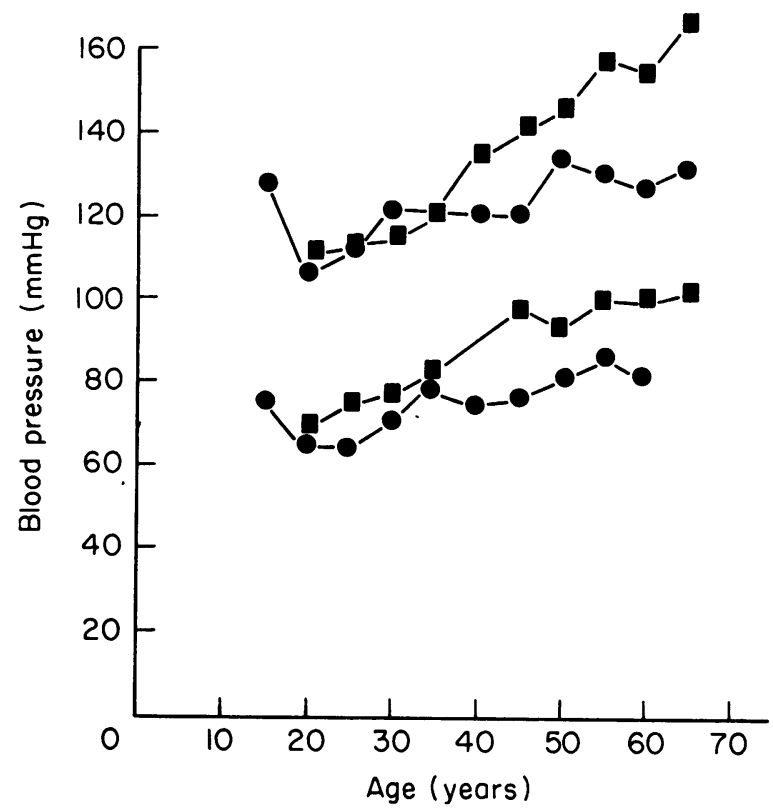

Fig. 6. Relationship between blood pressure and age in rural (O-O) and urban ( $\square-\square)$ Xhosa.

then the failure to demonstrate a clear correlation between sodium and blood pressure in the whole population may be explicable.

From recent studies (unpublished) it is likely that the time course of change in arterial pressure with urbanization is short, and the further unravelling of environmental and genetic influences on blood pressure may be better determined from longitudinal studies of individual migrants from 'low' to 'high' blood pressure areas.

\section{References}

Bianchi, G., Fox, U., di Francesco, G.F., Giovanetti, A.M. \& Pagetri, D. (1974) Blood pressure changes produced by kidney cross-transplanation between spontaneously hypertensive rats (SHR) and normotensive rats. Clinical Science and Molecular Medicine, 47, 435.

Dahl, L.K., Heine, M. \& TAssinari, L. (1962) Role of genetic factors in susceptibility to experimental hypertension due to chronic excess salt ingestion. Nature, 194, 480.

Feinleib, M., Garrison, R., Borhani, N., Rosenman, R. \& Christian, J. (1975) Studies of hypertension in twins. In: Epidemiology and Control of Hypertension (Ed by Paul, O.), p. 3-17. Stratton Intercontinental Medical Book Corp., New York.

HALlBÄCK, M. (1975) Consequence of social isolation on blood pressure, cardiovascular reactivity and design in spontaneously hypertensive rats. Acta physiologica scandinavica, 93, 455 .

LeVy, S.B., Lilley, J.J., Frigon, R.P. \& Stone, R.A. (1977) Urinary kallikrein and plasma renin activity as determinants of renal blood flow: the influence of race and dietary sodium intake. Journal of Clinical Investigation, 60, 129.

Luft, F.C., Grimm, C.E., Fineberg, N. \& Weinberger, M.E. (1979) Effects of volume expansion and contraction in normotensive whites, blacks and subjects of difference ages. Circulation, 59, 643.

Miall, W.E. \& ChINN, S. (1974) Screening for hypertension: some epidemiological observations. British Medical Journal, 3, 595.

Sever, P.S., Gordon, D., Peart, W.S. \& Beighton, P. (1980) Blood pressure and its correlates in urban and tribal Africa. Lancet, ii, 60.

Sever, P.S., Peart, W.S., Davies, I.B. \& Gordon, D. (1979a) Racial differences in blood pressure. 2. A hypertensive population. Clinical and Experimental Hypertension, 1, 745.

Sever, P.S., Peart, W.S., Meade, T.W., Davies, I.B. \& GoRDON, D. (1979b) Racial differences in blood pressure. 1. A 'normal' population. Clinical and Experimental Hypertension, 1, 733.

Tobian, L. (1977) Salt and hypertension. In: Hypertension (Ed by Genest, J., Koiw, E. \& Kuchel, O.) pp. 423-433. McGraw-Hill Book Company, New York.

Voors, A.W., Berenson, G.S., DAtFeres, E.R., Webber, L.S. \& SHuleR, W.E. (1979) Racial differences in blood pressure control. Science, 204, 1091. 